\title{
Variability of the Deep Overflow through the Kerama Gap Revealed by Observational Data and Global Ocean Reanalysis
}

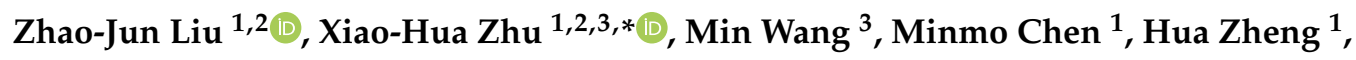 \\ Hirohiko Nakamura ${ }^{4}$, Ayako Nishina ${ }^{4}$ and Jae-Hun Park ${ }^{5}$ \\ 1 State Key Laboratory of Satellite Ocean Environment Dynamics, Second Institute of Oceanography, \\ Ministry of Natural Resources, Hangzhou 310012, China; zjliu@sio.org.cn (Z.-J.L.); \\ minmochen@sio.org.cn (M.C.); Zhenghua1995@yeah.net (H.Z.) \\ 2 Southern Marine Science and Engineering Guangdong Laboratory (Zhuhai), Zhuhai 519000, China \\ 3 School of Oceanography, Shanghai Jiao Tong University, Shanghai 200030, China; wangm0309@163.com \\ 4 Faculty of Fisheries, Kagoshima University, Kagoshima 890-0056, Japan; \\ nakamura@fish.kagoshima-u.ac.jp (H.N.); nishina@fish.kagoshima-u.ac.jp (A.N.) \\ 5 Department of Ocean Sciences, Inha University, Incheon 22839, Korea; jaehunpark@inha.ac.kr \\ * Correspondence: xhzhu@sio.org.cn; Tel.: +86-571-8196-3090
}

Received: 18 April 2020; Accepted: 30 May 2020; Published: 2 June 2020

\begin{abstract}
Herein, the temporal variability of the deep overflow through the Kerama Gap between the East China Sea and the Philippine Sea is investigated based on observational data combined with reanalysis data obtained during 2004-2011. The observations and model results show a strong bottom-intensified flow intruding into the deep Okinawa Trough. The observed deep overflow shows intraseasonal variations that are enhanced from August to November. The variability in the deep overflow via the Kerama Gap is well-correlated with the density changes near its sill depth in the Philippine Sea. Additionally, some portion of the dense water originates from a region east of Miyakojima, which can be related to the northeastward-flowing Ryukyu Current at intermediate depths. In contrast, three extreme deep overflow events indicate that the arriving mesoscale eddies propagated from the east resulted in an increase in the density near the Kerama Gap sill than that on the Okinawa Trough side. The density difference associated with the baroclinic pressure gradient across the Kerama Gap forced the deep overflow into the Okinawa Trough. The volume transport of the deep overflow computed by integrating the cross-sectional velocity and through hydraulic theory are 0.14 and $0.11 \mathrm{~Sv}\left(1 \mathrm{~Sv}=10^{6} \mathrm{~m}^{3} / \mathrm{s}\right)$, respectively.
\end{abstract}

Keywords: Kerama Gap; deep water overflow; observation; HYCOM reanalysis; variability; Ryukyu Current; mesoscale eddy

\section{Introduction}

The East China Sea (ECS) is separated from the western Philippine Sea by the Ryukyu Island chain (Figure 1). In the ECS, the Okinawa Trough is more than $2000 \mathrm{~m}$ deep. The Kuroshio enters and exits the ECS through the East Taiwan Channel (sill depth $775 \mathrm{~m}$ ) and Tokara Strait (sill depth $690 \mathrm{~m}$ ), carrying significant heat, salt, nutrients, and organic matter [1-4]. The northeastward Ryukyu Current flows along the continental slope, east of the Ryukyu Island chain [5-7]. The deepest passage connecting the ECS and western Philippine Sea is the Kerama Gap, located near the middle point of the Ryukyu Island chain. The Kerama Gap sill is approximately $50 \mathrm{~km}$ wide and $1050 \mathrm{~m}$ deep. 

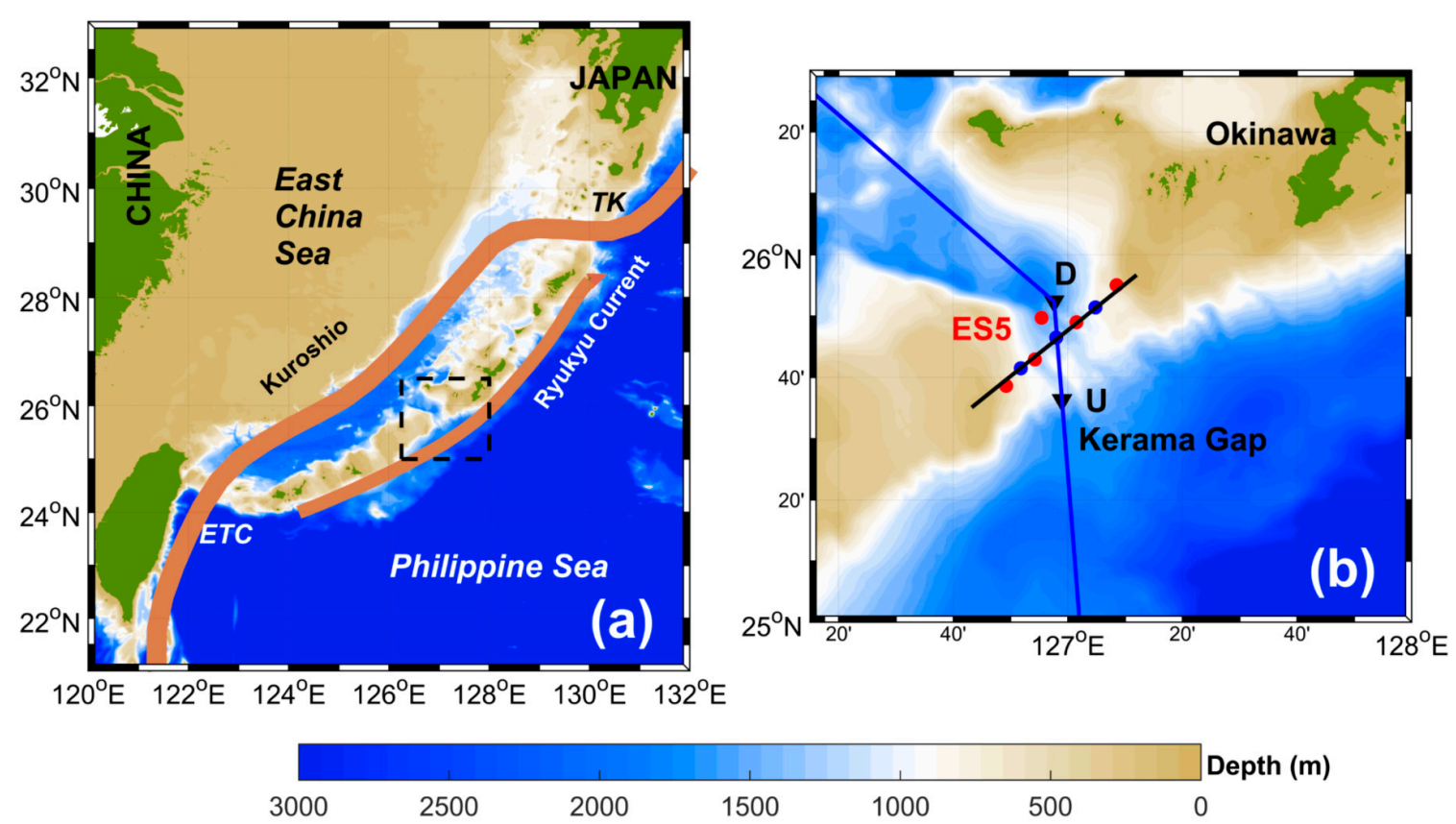

Figure 1. (a) Topography of the East China Sea and the Philippine Sea. JTOPO 30v2 topography data developed by the Marine Information Research Center (MIRC), Japan, is used. Orange curves indicate the paths of the Kuroshio and Ryukyu Currents. ETC and TK denote the East Taiwan Channel and Tokara Strait, respectively. (b) Close-up of the boxed region by dashed lines in (a). Red dots indicate the locations of CPIES moorings, ES5 shows the CPIES mooring deployed $7.4 \mathrm{~km}$ downstream of the Kerama Gap main sill during June 2009-June 2010. Blue dots indicate locations of current meter moorings. Black line denotes the HYCOM transect used to show the cross-sectional structure of the current through the Kerama Gap. Blue line denotes the transect used to show the density distribution along the Kerama Gap between the ECS and the Philippine Sea. Black triangles indicate the locations of selected point in upstream and downstream. U and D denote the upstream and downstream, respectively.

There has been one set of previous observations in the Kerama Gap comprising Current and Pressure-recording Inverted Echo Sounders (CPIES) and moored current meters [8]. Observations took place from June 2009 to June 2011. Na et al. [9] analyzed the above observational data and suggested that during the two-year observational period, the mean transport into the ECS from the Philippine Sea was $2.0 \pm 0.7 \mathrm{~Sv}\left(1 \mathrm{~Sv}=10^{6} \mathrm{~m}^{3} / \mathrm{s}\right)$. They further revealed that the temporal variability in the Kerama Gap transport plays an important role in determining the Kuroshio transport in the ECS, which is associated with the impinging mesoscale eddies propagated from the Pacific Ocean. Based on the global HYCOM (HYbrid Coordinate Ocean Model) reanalysis, Yu et al. [10] investigated the temporal variability in the transport through the Kerama Gap at much longer timescales. They showed that the transport had significant seasonal variability, with a maximum in October and minimum in November, which is explained by annual variations, mesoscale eddies, and Kuroshio meander. Furthermore, Yu et al. [11] studied the causes of the extreme cases of the Kerama Gap overflow based on the same HYCOM reanalysis data and found that the most important factor is mesoscale eddies. Zhou et al. [12] reported that the variation in the Kuroshio transport across the PN-line (a repeat hydrographic section crossing the Kuroshio in the ECS northwest of Okinawa) is associated with the water exchange between the Philippine Sea and ECS through the Kerama Gap by utilizing HYCOM reanalysis data. Notably, the above mentioned studies focused their attention solely on the upper and intermediate water exchange and overlooked the deep water overflow through the Kerama Gap.

Previous studies suggested that the Kerama Gap deep water overflow can ventilate the Okinawa Trough deep water below $1000 \mathrm{~m}$ [13]. Additionally, the deep water overflow is energetic with the 
velocity at the sill of up to $50 \mathrm{~cm} / \mathrm{s}$. Nakamura et al. [13] suggested that the deep water overflow is probably topographically controlled and predicted the Kerama Gap deep water overflow to be approximately $0.18-0.35 \mathrm{~Sv}$ using a simple box model.

The swift deep water overflow of the Kerama Gap is accompanied by strong turbulence and intense mixing in the Okinawa Trough [13,14]. Using comprehensive observational data, Nishina et al. [14] indicated that hydraulic jumps occurring over the Kerama Gap sills possibly caused strong vertical diffusivity $\left(\sim 10^{-1} \mathrm{~m}^{2} / \mathrm{s}\right)$. Their results showed that the Kerama Gap deep overflow can ventilate the deep water below approximately $1100 \mathrm{~m}$ depth in the Okinawa Trough, and the residence time in the southern Okinawa Trough is approximately 5-10 years. Therefore, the deep overflow through the Kerama Gap plays an important role in the deep ventilation in the Okinawa Trough. However, these studies argue that the mean state of the deep water overflow in the Kerama Gap given by the observational data is not sufficiently long. Thus far, understanding the variability in the deep overflow through the Kerama Gap has required further study.

Similar to the Luzon Strait connecting the deep Philippine Sea circulation with the South China Sea throughflow, the deep water circulation in the Kerama Gap also dynamically controls the water mass distribution and circulation in the deep layer of the southern Okinawa Trough. Thus far, many efforts have been made in terms of the deep water overflow via the Luzon Strait to address the following questions: (1) How does the deep water overflow vary? (2) What factors control the variability in the deep water overflow? (3) How does the deep water circulation in the strait influence the circulation in the South China Sea? However, the above questions are still unknown in the Kerama Gap region, even though these are important in understanding the deep water circulation in the ECS.

In this study, we investigate the temporal variation in the Kerama Gap deep overflow using eight years of HYCOM reanalysis output. The organization of the present paper is as follows. In Section 2, observational data and assimilation data are briefly introduced. Variability and causes of the deep overflow through the Kerama Gap are examined in Section 3. The summary and discussion are presented in Section 4.

\section{Data and Methods}

\subsection{Mooring Measurement}

In the period of 7 June 2009-6 June 2011, a tightly spaced mooring array straddled the Kerama Gap sill. This array was configured with five CPIESs and three current meter moorings. In this array, one CPIES instrument (ES5) was deployed approximately $7.4 \mathrm{~km}$ downstream of the Kerama Gap main sill during 7 June 2009-6 June 2010 (red dot shown in Figure 1). The CPIES was equipped with an Aanderaa current meter (Model 3820R) positioned $50 \mathrm{~m}$ above the seafloor. The typical accuracy in the raw velocity data is $\pm 1.0 \mathrm{~cm} / \mathrm{s}$. Raw current data were recorded every $1 \mathrm{~h}$ and corrected based on the local magnetic declination. A low-pass filter with a cutoff period of $72 \mathrm{~h}$ was optimized to remove the major semidiurnal and diurnal tidal constituents and near-inertial signals $(\sim 27 \mathrm{~h})$ near the Kerama Gap. Finally, all currents were subsampled to a frequency of once per day. The observational data return and processing details are found in Liu et al. [8].

\subsection{Numerical Model}

In this study, HYCOM reanalysis outputs were used to examine the variability in the deep overflow via the Kerama Gap. In the HYCOM reanalysis, observed sea surface temperature, sea surface height, and sea ice concentration were assimilated using the Navy Coupled Ocean Data Assimilation (NCDA) [15]. HYCOM reanalysis can be applied widely, from coastal to planetary scales. Horizontal resolution of HYCOM is $1 / 12^{\circ}$ (approximately $9 \mathrm{~km}$ ), with 32 vertical hybrid layers configured. These hybrid layers are expressed in $\mathrm{z-}$, sigma-, and isopycnal coordinates in unstratified water, shallow depths, and stratified ocean, respectively. 
Compared to other reanalysis data, HYCOM is advantageous to use in deep overflow studies of the Kerama Gap. It can solve the complex topography around the Ryukyu Island chain and further simulate the surrounding circulation. Several studies have employed the HYCOM reanalysis for the Ryukyu Island chain region [10-12,16,17]. Recent studies have suggested that this HYCOM reanalysis efficiently represent deep sea dynamics as it is isopycnic and can efficiently represent the horizontal pressure in an adiabatic fluid [18]. For example, Du et al. [19] employed HYCOM to successfully simulate the transport mechanism in the ocean interior. Zhao et al. [20] used HYCOM and suggested that deep circulation in the Luzon Strait is primarily driven by a baroclinic pressure gradient across the strait. These examples indicated the suitability of the model for simulating the deep water overflow through the Kerama Gap.

\section{Results}

In this section, we first provide the variability in the Kerama Gap deep water overflow based on the observational data in Section 3.1; then, we elucidate the mechanism of the variability using the HYCOM reanalysis data in Section 3.2.

\subsection{Temporal Variability Based on Observational Data}

Figure $2 \mathrm{~b}$ shows the current vector time series of the deep overflow at $50 \mathrm{~m}$ above the Kerama Gap bottom obtained from the current meter on the CPIES mooring at ES5 (bottom depth: $1416 \mathrm{~m}$, see Figure $1 \mathrm{~b}$ for its location). The mean speed \pm standard deviation of the deep overflow is $25.4 \pm 6.4 \mathrm{~cm} / \mathrm{s}$. It is clear that the deep overflow generally follows the local bottom topography. The flow near the bottom at ES5 is a fairly strong and steady current, directed northeastward (18.7 clockwise from north to east) throughout the observational period (Figure 2a).
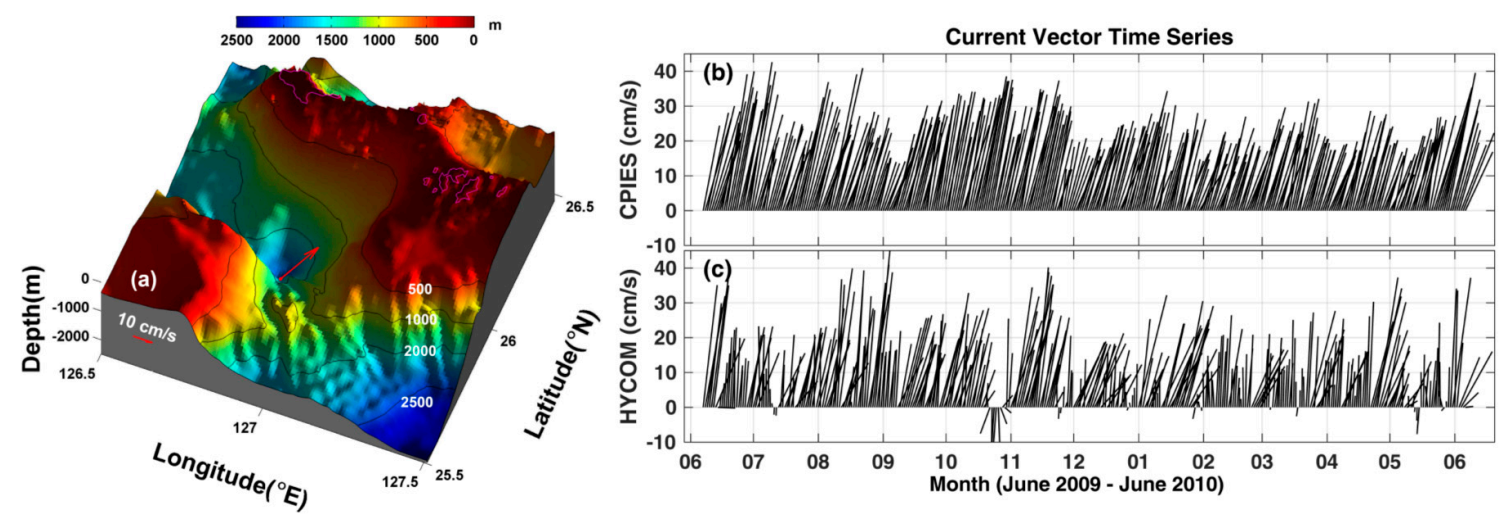

Figure 2. (a) Three-dimensional topography around the Kerama Gap. The red vector indicates the mean current vector obtained from the CPIES instrument during June 2009-June 2010. The black contour lines represent the 500, 1000, 2000, and $2500 \mathrm{~m}$ isobaths, respectively. (b) Daily mean current vector time series during June 2009-June 2010 for the depth $50 \mathrm{~m}$ above the bottom at ES5. (c) Same as (b) but obtained from the HYCOM data for the $1000 \mathrm{~m}$ depth.

To investigate the temporal variability in the deep water overflow, we first analyze the wavelet power spectrum (using Torrence and Compo wavelet toolbox) and the global wavelet spectrum (GWS) of the eastward and northward velocity (Figure 3). Both the eastward and northward velocities show statistically significant (95\%) energy peaks with periods near 100, 15-60 days (Figure 3c,d). These period bands are also found in the volume transport variability in the upper and intermediate layers through the Kerama Gap, as reported by Yu et al. [10]. Meanwhile, the length of the observational data is just one year; thus, the inter-annual and annual variation in the deep water overflow in this gap cannot be addressed with this data. Furthermore, wavelet analysis of the eastward and northward velocity of 
the deep overflow at ES5 indicates that intraseasonal variations enhance from August to November during the period of 2009-2010 (Figure 3a,b).
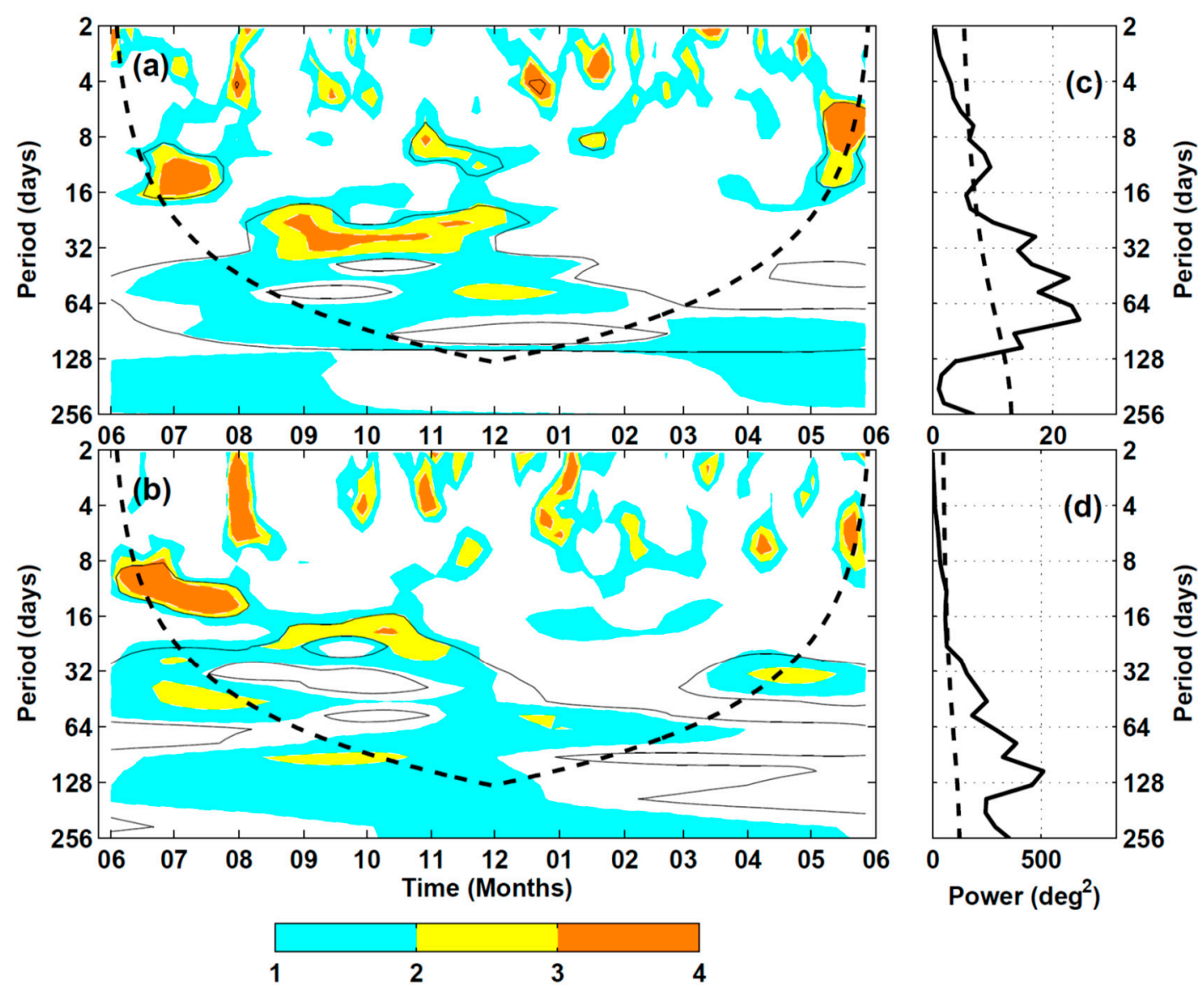

Figure 3. Wavelet power spectrum (using the Morlet wavelet) of the (a) northward and (b) eastward velocity at ES5 normalized by the global wavelet spectrum (GWS) shown in (c) and (d). The enclosed regions by thick black contours denote regions of greater than $95 \%$ confidence of a red-noise process. Black dashed lines indicate that the area below is subject to the edge effect.

\subsection{Causes of Temporal Variability}

In this section, the detailed mechanism of the deep water overflow via the Kerama Gap is further investigated based on HYCOM reanalysis data. Figure 4 provides a sectional view of the mean cross-sectional velocity of the deep overflow through the Kerama Gap in the period of June 2009-June 2010. The Kerama Gap is characterized by a bottom-intensified flow, with a maximum velocity of up to $25 \mathrm{~cm} / \mathrm{s}$ (positive into the Okinawa Trough). To evaluate the capability of the HYCOM data, the current vector time series obtained from the HYCOM reanalysis and measured data are compared, as shown in Figure 2. The time series for the same location as the CPIES at ES5 is used. Notably, the current velocity at $1000 \mathrm{~m}$ depth is used, since the water depth of the HYCOM reanalysis is $1000 \mathrm{~m}$ near the Kerama Gap sill. Generally, the modeled velocity time series is consistent with the observed time series. HYCOM also exhibited a strong and stable current near the bottom, with the mean velocity \pm standard deviation as $19.0 \pm 9.5 \mathrm{~cm} / \mathrm{s}$. The minimum-to-maximum range of velocity was approximately 2.7 times larger than the mean value. The standard deviation of the HYCOM velocity $(9.5 \mathrm{~cm} / \mathrm{s})$ was approximately 1.4 times larger than that of the observed velocity $(6.7 \mathrm{~cm} / \mathrm{s})$, while its mean $(19.0 \mathrm{~cm} / \mathrm{s})$ was $75 \%$ of the observed mean $(25.4 \mathrm{~cm} / \mathrm{s})$. The relatively weaker deep overflow captured by the HYCOM reanalysis can be attributed to the HYCOM topography, which was significantly coarser than the true topography. 


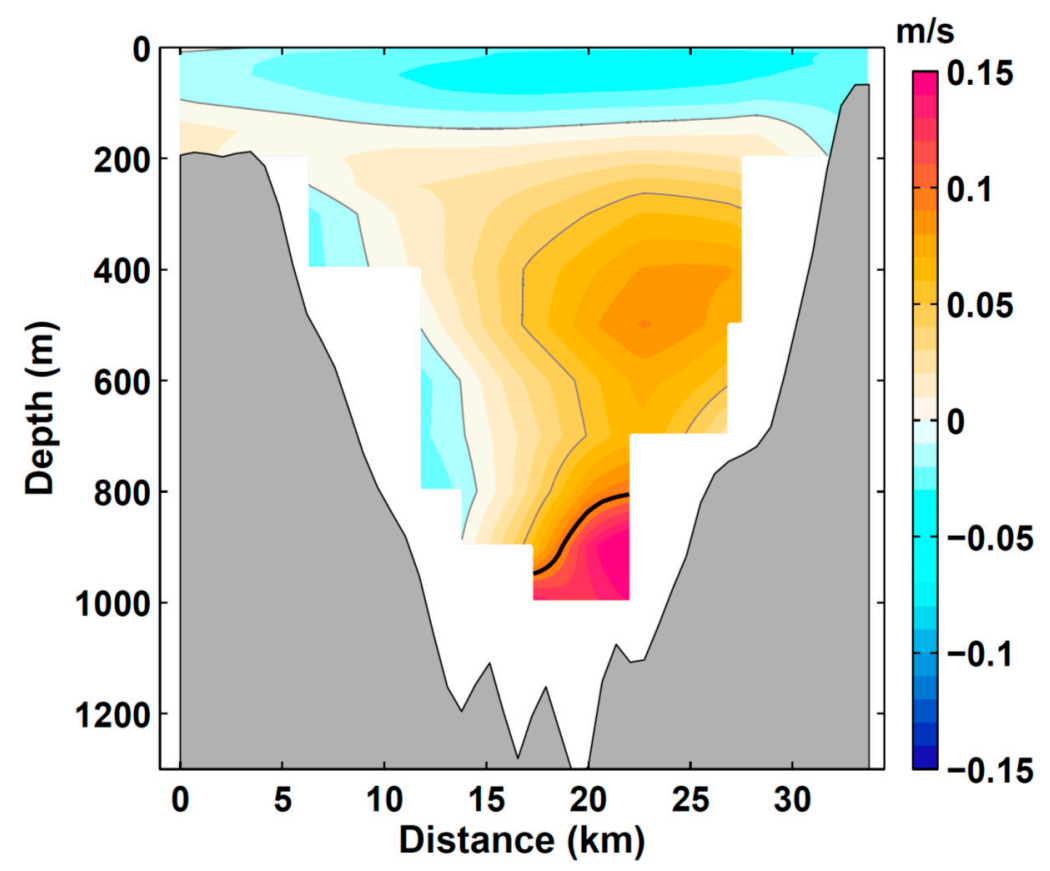

Figure 4. Mean cross-sectional structure of current velocity through the Kerama Gap (see Figure 1b for section location) obtained from the HYCOM reanalysis data during June 2009-June 2010 (positive into the Okinawa Trough). The contours represent 0 and $5 \mathrm{~cm} / \mathrm{s}$. The thick black contour denotes $10 \mathrm{~cm} / \mathrm{s}$ below $800 \mathrm{~m}$ depth. Gray shade denotes the bottom topography along the section based on JTOPO $30 \mathrm{v} 2$ topography data.

As reported by Nakamura et al. [13] and Nishina et al. [14], the deep water overflow of the Kerama Gap is driven by a persistent baroclinic pressure gradient owing to the density difference between the Philippine Sea and the Okinawa Trough; in other words, significant density differences exist between two sides of the Kerama Gap. As shown in Figure 5, the absolute velocity time series of the deep overflow (black) is well correlated with the time series of the density differences between the Philippine Sea and the southern Okinawa Trough at depth $1000 \mathrm{~m}$ (blue, $\mathrm{r}=0.72$, significant at the $95 \%$ confidence level). The correlation coefficients between the absolute velocity time series and the upstream (red) and downstream (green) densities at depth $1000 \mathrm{~m}$ are 0.73 and 0.35 , respectively. This implies that the deep water overflow variation in the Kerama Gap can be determined by the variability in the density in the Philippine Sea.

Because the dynamic environment of the upstream region is relatively complex, i.e., comprising the Ryukyu Current and mesoscale eddies from the east, it is important to examine the cause of the variability in the upstream density at $1000 \mathrm{~m}$. Therefore, we plot the correlation maps between the upstream density at $1000 \mathrm{~m}$ and densities at 1000, 1100, 1200, and $1300 \mathrm{~m}$ in the surrounding region (Figure 6). While computing the correlation, time series of two variables were used. One variable was density at $1000 \mathrm{~m}$ depth in the selected upstream point (location: black triangle shown in Figure 1b), and the other variable was density at $1000 \mathrm{~m}$ (or 1100, 1200, $1300 \mathrm{~m}$ ) depth at each grid point around the Kerama Gap. Then, Pearson's linear correlation coefficient between each two time series was calculated. The statistical significance of the correlation coefficients was estimated using a Student's $t$ test. It is clear that the upstream density at depth $1000 \mathrm{~m}$ is responsible for the region southeast of the Kerama Gap along the submarine Ryukyu Island chain. This is because the Kerama Gap overflow originates from a branch of the northeastward Ryukyu Current off the eastern slope of the Ryukyu Island chain at intermediate depths [6,21-25]. 


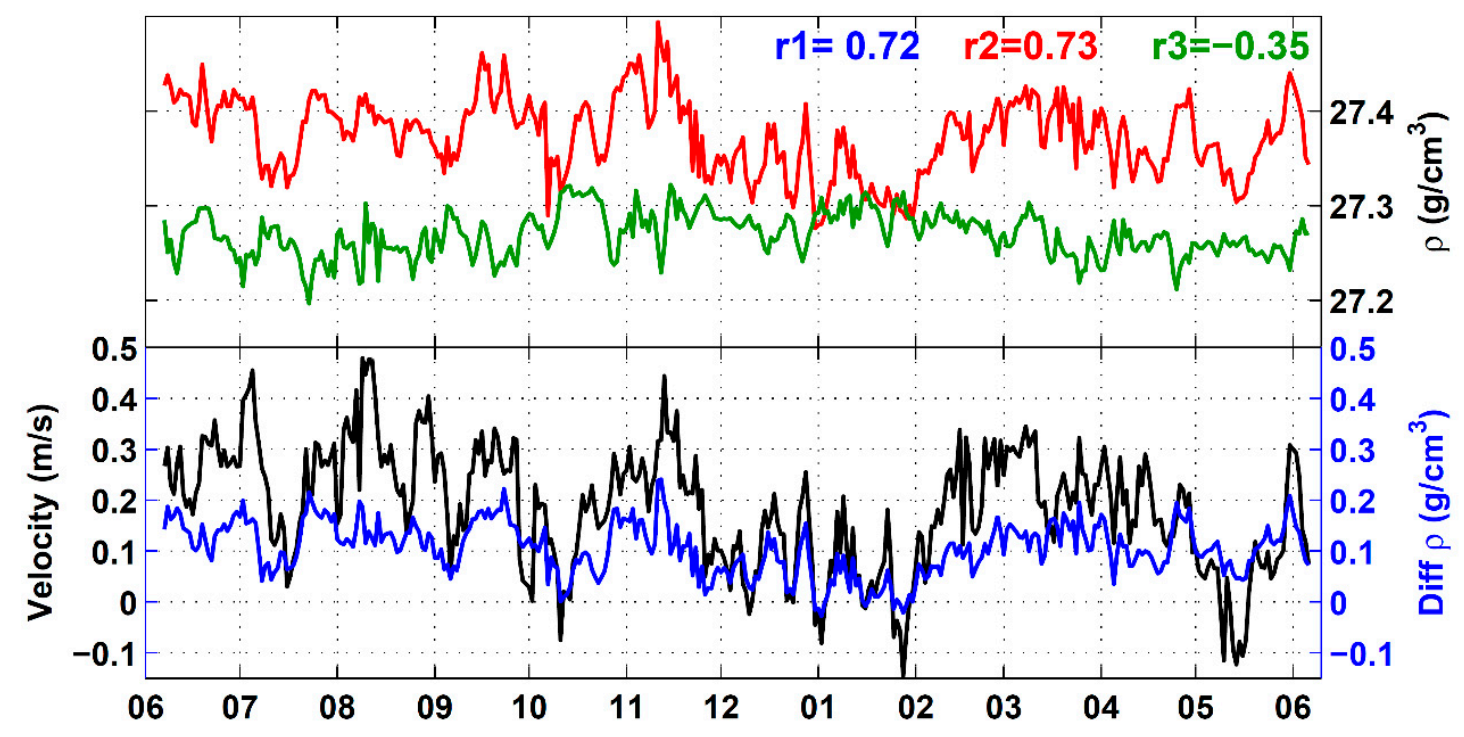

Figure 5. Time series of the absolute velocity at ES5 obtained from HYCOM reanalysis data (black, unit: $\mathrm{m} / \mathrm{s}$ ). The density difference between the upstream and downstream at $1000 \mathrm{~m}$ depth (unit: $\mathrm{g} / \mathrm{cm}^{3}$ ), density of upstream, and density of downstream at $1000 \mathrm{~m}$ depth (unit: $\mathrm{g} / \mathrm{cm}^{3}$ ) are superimposed and shown in blue, red, and green, respectively. The corresponding correlation coefficients between the two time series are given at the top.
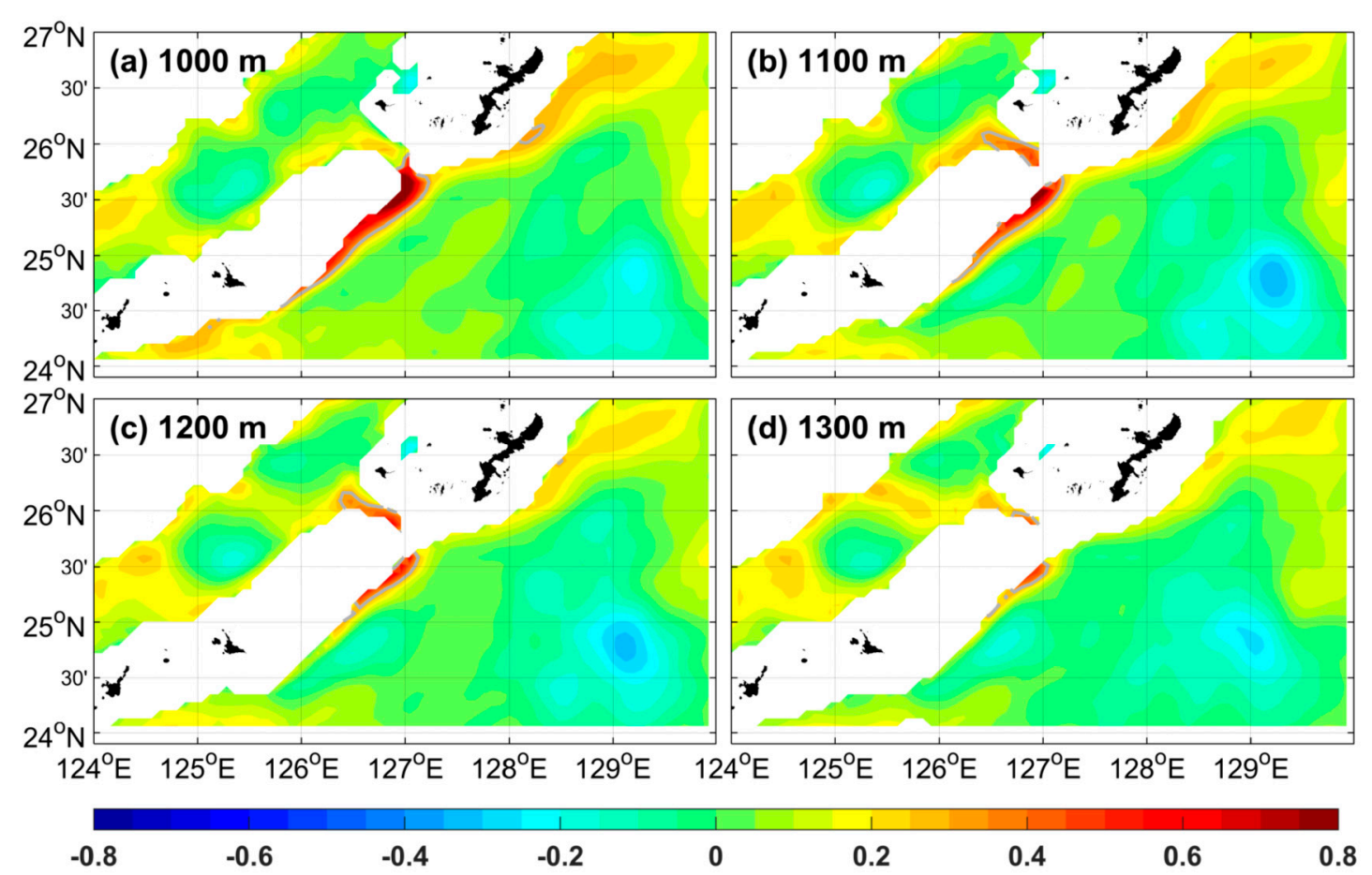

Figure 6. Maps of correlation between the Kerama Gap upstream density at $1000 \mathrm{~m}$ depth and the densities at (a) 1000, (b) 1100, (c) 1200, and (d) 1300 m depth surrounding the Kerama Gap. The gray contour indicates where the correlation coefficient equals 0.5 (statistically significant at the $95 \%$ confidence level). 
According to Whitehead et al. [26], Partt et al. [27], and Qu et al. [28], if the local gap width is larger than or comparable with the local internal Rossby radius, the volume transport of the deep water overflow through the Kerama Gap can be estimated as:

$$
\mathrm{Q}=\frac{g^{\prime} h_{u}^{2}}{2 f} \text { for } \mathrm{L}>\sqrt{2} R=\left(\frac{2 g^{\prime} h_{u}}{f^{2}}\right)^{1 / 2}
$$

where $g^{\prime}=g \frac{\Delta \rho}{\rho}$ is the reduced gravity, $g$ is the gravity acceleration, $\Delta \rho$ is the density difference between the upstream and downstream at $1000 \mathrm{~m}$ depth, $\rho$ is the average density near the Kerama Gap sill depth $(1000 \mathrm{~m}), h_{u}$ is the interface height above the gap sill depth separating the two layers, $f$ is the Coriolis parameter, and $R=\left(\frac{g^{\prime} h_{u}}{f^{2}}\right)^{1 / 2}$ is the Rossby radius. Figure 7a shows the estimated volume transport time series of deep overflow based on Formula (1), and the corresponding time series for $h_{u}$ is shown in Figure $7 \mathrm{~b}$. Notably, the bifurcation depth in the calculation is chosen as the depth at which $\Delta \rho<0.05 \mathrm{~kg} / \mathrm{m}^{3}$. The mean deep overflow transport in the period of January 2004-June 2011 is approximately $0.11 \mathrm{~Sv}$, and the mean depth of the deep overflow ranges from 800 to $1000 \mathrm{~m}$.


Figure 7. (a) Volume transport of the deep water overflow during January 2004-June 2011 estimated based on hydraulic theory (gray), and the volume transport computed by directly integrating the cross-sectional velocity (see Figure 4 a for section location) larger than $10 \mathrm{~cm} / \mathrm{s}$ below $800 \mathrm{~m}$ are shown in red color. The mean volume transports \pm standard deviations are shown in the top left of panel (a) in the corresponding color. (b) Variation in the density difference between the upstream and downstream densities from 500 to $1000 \mathrm{~m}$ depth during January 2004-June 2011.

To understand the contribution of the hydraulic control component to the total deep overflow, we also compute the volume transport of the deep overflow based on the mean integrated cross-sectional velocity during 2004-2011, for velocities larger than $5 \mathrm{~cm} / \mathrm{s}$, at depths ranging from $800 \mathrm{~m}$ to $1000 \mathrm{~m}$ (gray line in Figure 7a). In this method, the mean and standard deviation of the integrated volume transport was $0.14 \pm 0.17 \mathrm{~Sv}$, whereas the estimated transport based on the hydraulic theory was 
approximately $0.11 \mathrm{~Sv}$, with a standard deviation of $\pm 0.28 \mathrm{~Sv}$. In other words, the hydraulic control component is about 79\% of the total deep overflow. Moreover, according to Na et al. [9] and Yu et al. [10], both the observed and modeled through-passage transport in the upper and intermediate layers, except the deep water overflow, total approximately $2.0 \mathrm{~Sv}$. Hence, the volume transport of the deep water overflow is approximately $6 \%$ of the transport through the upper and intermediate layers, even though the deep water overflow occurs only in the layer above 100-200 m above the bottom. In addition, with a linear fit from January 2004 to June 2011, the deep overflow transport increased by $0.03 \mathrm{~Sv}$ per year, suggesting an increasing deep overflow during this period. This may be related to decadal or significantly longer time scale variations in the dynamic environment around the Kerama Gap. However, detailed examination of this mechanism was beyond the scope of this study and will be explored in future research.

Significantly strong deep overflow (deep overflow transport was approximately 15 times larger than the mean value) was exhibited during three periods, 17 September 2006, 17 January 2009, and 24 April 2011. In the following, we will show these three cases in detail, especially the dynamical environment. Figure 8a shows the sea level anomaly on 24 April 2011, obtained from the HYCOM reanalysis data, which indicated that a cyclonic eddy was located in the southeast section of the Kerama Gap. The density upstream is much larger than that downstream, even at $600 \mathrm{~m}$ depth (Figure 9a). The density difference between the upstream location and downstream location is $0.18 \mathrm{~kg} / \mathrm{m}^{3}$ at $1000 \mathrm{~m}$ depth (Figure 9d). The larger density difference between both sides of the gap forces denser Philippine Sea water entering the southern Okinawa Trough via the Kerama Gap. Just as in the case of 24 April 2011, the density difference between the two sides of the Kerama Gap is the largest on 17 January $2009\left(0.28 \mathrm{~kg} / \mathrm{m}^{3}\right.$ at $1000 \mathrm{~m}$ depth, see Figure 9e), which also drives denser water flow into the Okinawa Trough from the North Pacific (Figure 8b). However, different from the case of 24 April 2011, an anticyclonic eddy is on the east side of the Ryukyu Island chain, which tries to intrude into the Okinawa Trough via the Kerama Gap (Figure 8b). In the final case, density differences also exist between the North Pacific and the Okinawa Trough but much smaller than the previous two cases $\left(0.15 \mathrm{~kg} / \mathrm{m}^{3}\right.$ at $1000 \mathrm{~m}$ depth, see Figure 9c,f). Moreover, the Ryukyu Current bifurcates into the deep overflow via the Kerama Gap and northeastward Ryukyu Current (Figure 8c).

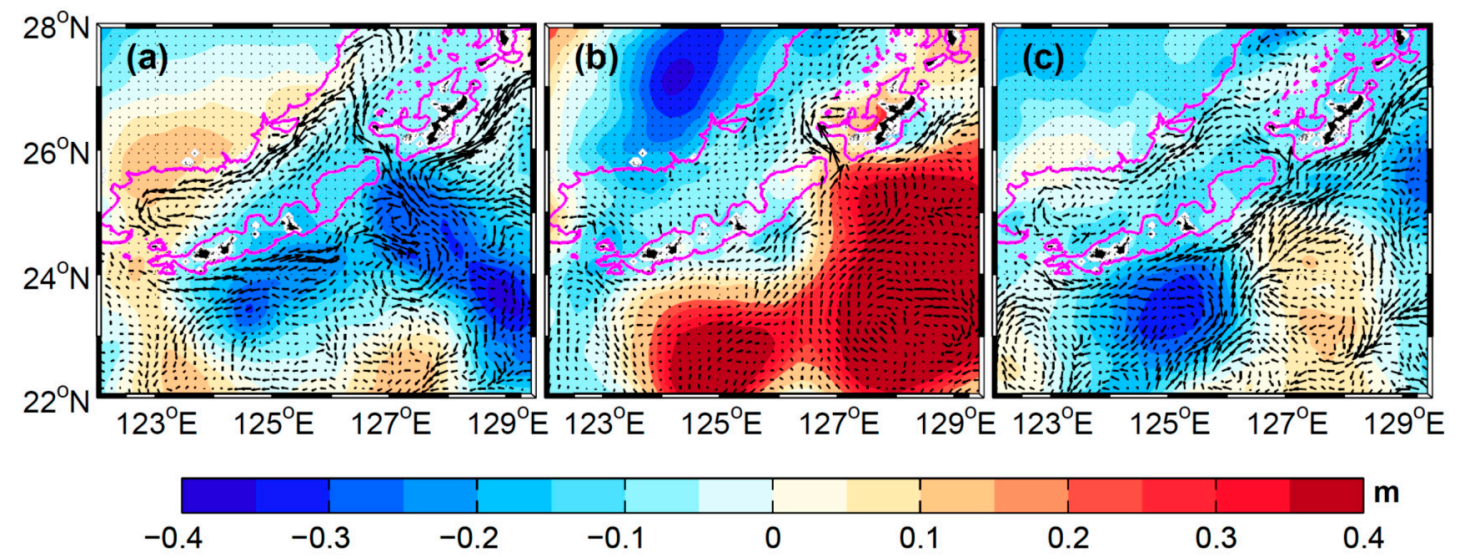

Figure 8. Horizontal velocity fields at $1000 \mathrm{~m}$ depth on (a) 24 April 2011, (b) 17 January 2009, and (c) 17 September 2006, respectively. Color shade shows the sea level anomaly obtained from HYCOM analysis output. Pink contour lines refer to $500 \mathrm{~m}$ isobaths. 


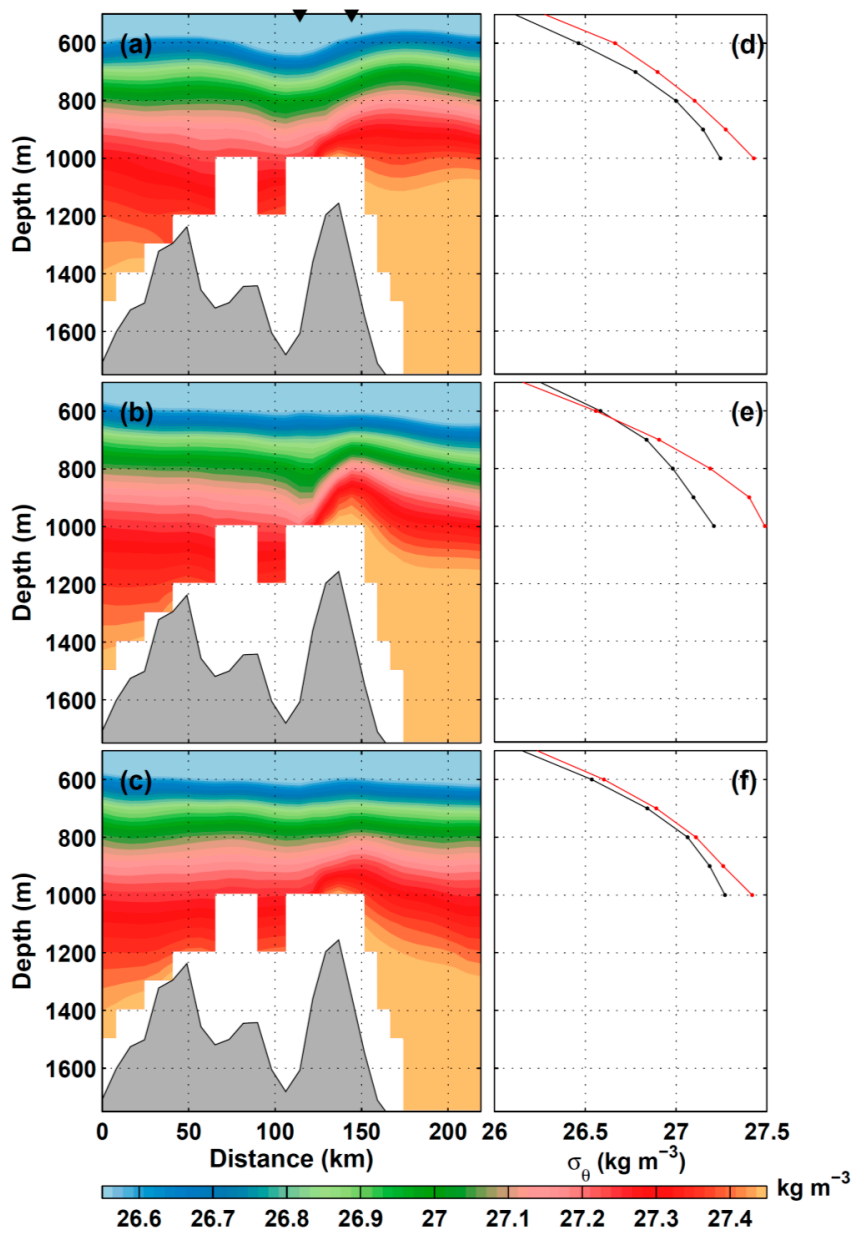

Figure 9. The $\sigma_{\theta}$ density along the transect as shown in Figure 1 b on (a) 24 April 2011, (b) 17 January 2009, and (c) 17 September 2006, respectively. Black triangles shown at the top of Figure 9a denote the location of downstream (left) and upstream (right). Gray shade denotes bottom topography along the section based on JTOPO 30v2 topography data. Corresponding vertical profiles for the upstream location (red) and downstream location (black) are shown in (d)-(f).

\section{Summary and Discussion}

Observational data from a current meter and output from HYCOM reanalysis data from 2004 to 2011 were used to investigate the variability in the deep water overflow through the Kerama Gap, the deepest channel of the Ryukyu Island chain and a key pathway between the Philippine Sea and the ECS.

Current records from June 2009 to June 2010 indicate that the deep water overflow in the Kerama Gap is fairly strong, with a mean velocity of approximately $25.4 \mathrm{~cm} / \mathrm{s}$ and a standard deviation of $6.4 \mathrm{~cm} / \mathrm{s}$. Moreover, one-year observations reveal that the deep overflow shows statistically significant (90\%) spectral peaks, with periods of approximately 100 days, 37-60 days, and 21 days, and the intraseasonal variations become enhanced from August to November based on observational data.

By analyzing the HYCOM analysis data, we find that the absolute velocity time series of the deep overflow at ES5 is well correlated with the time series of the density differences between the Philippine Sea and the Okinawa Trough at depth $1000 \mathrm{~m}(\mathrm{r}=0.72$, significant at the 95\% confidence level). Additionally, the variability in the deep overflow in the Kerama Gap is much better correlated with the density in the Philippine Sea than with that in the Okinawa Trough. This implies that the variations of the deep overflow may be related to the variability occurring in the Philippine Sea. The density variability in the Philippine Sea results from at least two factors: (1) the northeastward-flowing Ryukyu Current off the eastern slope of the Ryukyu Island chain at intermediate depths, which can induce 
upstream density near the Kerama Gap sill depth when it passes the gap and (2) the impinging mesoscale eddies propagated from the North Pacific, which induce a density difference between the two sides of the Kerama Gap and then force the deep overflow through the Kerama Gap.

Notably, the mean estimated volume transport based on hydraulic control theory using the HYCOM reanalysis data is relatively smaller than that using observational data. According to Nakamura et al. [13] and Nishina et al. [14], the deep water near the Kerama Gap sill originated from the West Philippine Sea, intruding into the deep layer of the Okinawa Trough. This process induces strong turbulent mixing immediately with light water upwelling. Meanwhile, the turbulent mixing in the Okinawa Trough plays a key role in driving the denser water intruding into the Okinawa Trough. Hence, we suggest that the relatively weaker deep overflow in the HYCOM may be related to the relatively weaker turbulent mixing occurring in the Okinawa Trough, since the sea water stratification of the HYCOM is relatively stronger than that of the real ocean.

Water mass formation in the deep layer of the Okinawa Trough is related to the deep water overflow through the Kerama Gap. In future study, more intensified observations should be conducted in the Kerama Gap region. Furthermore, the use of observational data along with numerical experiments is needed to address the question of how the deep water overflow drives the deep circulation in the southern Okinawa Trough.

Author Contributions: Z.-J.L. analyzed the observation data and made calculation. H.N., A.N., and J.-H.P. made contributions to experiment and data collection. Z.-J.L., X.-H.Z., M.W., M.C. and H.Z. took part in manuscript preparation and edition. All authors have read and agreed to the published version of the manuscript.

Funding: This study was mainly supported by the National Natural Science Foundation of China (grant numbers 41906023, 41920104006, 41776107, 41906024), the Japan Society for the Promotion of Science (JSPS) KAKENHI (15H05821, 15H03725), the Scientific Research Fund of the State Key Laboratory of Satellite Ocean Environment Dynamics, Second Institute of Oceanography (SOEDZZ1901), "Study on air-sea interaction and process of rapidly intensifying typhoon in the Northwestern Pacific" funded by the Ministry of Ocean and Fisheries, Korea.

Conflicts of Interest: The authors declare no conflict of interest.

\section{References}

1. Nitani, H. Beginning of the Kuroshio. In Kuroshio: Its Physical Aspects; Stommel, H., Yoshida, K., Eds.; University of Tokyo Press: Tokyo, Japan, 1972; pp. 129-163.

2. Oka, E.; Kawabe, M. Characteristics of variations of water properties and density structure around the Kuroshio in the East China Sea. J. Oceanogr. 1998, 54, 605-617. [CrossRef]

3. Andres, M.; Wimbush, M.; Park, J.H.; Chang, K.I.; Lim, B.H.; Watts, D.R.; Ichikawa, H.; Teague, W.J. Observations of Kuroshio flow variations in the East China sea. J. Geophys. Res. 2008, 113, C05013. [CrossRef]

4. Andres, M.; Park, J.H.; Wimbush, M.; Zhu, X.H.; Chang, K.I.; Ichikawa, H. Study of the Kuroshio/Ryukyu Current system based on satellite-altimeter and in situ measurements. J. Oceanogr. 2008, 64, 937-950. [CrossRef]

5. Yuan, Y.; Kaneko, A.; Su, J.; Zhu, X.H.; Liu, Y.; Gohda, N.; Chen, H. The Kuroshio east of Taiwan and in the East China sea and the Currents east of Ryukyu Islands during early summer of 1996. J. Oceanogr. 1998, 54, 217-226. [CrossRef]

6. Zhu, X.H.; Han, I.S.; Park, J.H.; Ichikawa, H.; Murakami, K.; Kaneko, A. The northeastward current southeast of Okinawa Island observed during November 2000 to August 2001. Geophys. Res. Lett. 2003, 30, 1071. [CrossRef]

7. Jin, B.; Wang, G.; Liu, Y.; Zhang, R. Interaction between the East China Sea Kuroshio and the Ryukyu Current as revealed by the self-organizing map. J. Geophys. Res. 2010, 115, C12047. [CrossRef]

8. Liu, Z.; Na, H.; Nakamura, H.; Nishina, A.; Park, J.-H.; Tracey, K.; Wimbush, M. Kerama Gap 2009-2011 data report. In GSO Technical Report 2012-02; Graduate School of Oceanography, University of Rhode Island: Narragansett, RI, USA, 2012.

9. Na, H.; Wimbush, M.; Park, J.-H.; Nakamura, H.; Nishina, A. Observations of flow variability through the Kerama Gap between the East China Sea and the Northwestern Pacific. J. Geophys. Res. Oceans 2014, 119, 689-703. [CrossRef] 
10. Yu, Z.; Metzger, E.J.; Thoppil, P.; Hurlburt, H.E.; Zamudio, L.; Smedstad, O.M.; Na, H.; Nakamura, H.; Park, J.-H. Seasonal cycle of volume transport through Kerama Gap revealed by a 20-year global Hybrid Coordinate Ocean Model reanalysis. Ocean Model. 2015, 96, 203-213. [CrossRef]

11. Yu, Z.; Metzger, E.J.; Hurlburt, H.E.; Smedstad, O.M. What controls the extreme flow through the Kerama Gap: A HYbrid Coordinate Ocean Model reanalysis point of view. Ocean Dynam. 2019, 69, 899-911. [CrossRef]

12. Zhou, W.; Yu, F.; Nan, F. Water exchange through the Kerama Gap estimated with a 25-year Pacific HYbrid Coordinate Ocean Model. Chin. J. Oceanol. Limnol. 2017, 35, 1287-1302. [CrossRef]

13. Nakamura, H.; Nishina, A.; Liu, Z.; Tanaka, F.; Wimbush, M.; Park, J.-H. Intermediate and deep water formation in the Okinawa Trough. J. Geophys. Res. Oceans 2013, 118, 6881-6893. [CrossRef]

14. Nishina, A.; Nakamura, H.; Park, J.-H.; Hasegawa, D.; Tanaka, Y.; Seo, S.; Hibiya, H. Deep ventilation in the Okinawa Trough induced by Kerama Gap overflow. J. Geophys. Res. Oceans 2016, 121, 6092-6102. [CrossRef]

15. Bleck, R. An oceanic general circulation model framed in hybrid isopycnic-Cartesian coordinates. Ocean Model. 2002, 4, 55-88. [CrossRef]

16. Thoppil, P.G.; Metzger, E.J.; Hurlburt, H.E.; Smedstad, O.M.; Ichikawa, H. The current system east of the Ryukyu Islands as revealed by a global ocean reanalysis. Prog. Oceanogr. 2016, 141, 239-258. [CrossRef]

17. Wang, M.; Liu, Z.; Zhu, X.; Yan, X.; Zhang, Z.; Zhao, R. Origin and formation of the Ryukyu Current revealed by HYCOM reanalysis. Acta Oceanol. Sin. 2019, 38, 1-10. [CrossRef]

18. Metzger, E.J.; Smedstad, O.M.; Thoppil, P.G.; Hurlburt, H.E.; Cummings, J.A.; Wallcraft, A.J.; Zamudio, L.; Franklin, D.S.; Posey, P.G.; Phelps, M.W.; et al. Us Navy operational global ocean and Arctic ice prediction systems, special issue on navy operational models. Oceanography 2014, 27, 32-43. [CrossRef]

19. Du, Y.; Wang, D.; Zhou, W.; Wang, W.; Liu, X. Intercomparsion of three South China Sea circulation models. Acta Oceanol. Sin. 2004, 23, 41-50.

20. Zhao, W.; Zhou, C.; Tian, J.; Yang, Q.; Wang, B.; Xie, L.; Qu, T. Deep water circulation in the Luzon Strait. J. Geophys. Res. Oceans 2014, 119, 790-804. [CrossRef]

21. Ichikawa, H.; Nakamura, H.; Nishina, A.; Higashi, M. Variability of northeastward current southeast of northern Ryukyu Islands. J. Oceanogr. 2004, 60, 351-363. [CrossRef]

22. Zhu, X.H.; Park, J.H.; Kaneko, I. The northeastward current southeast of the Ryukyu Islands in the late fall of 2000 estimated by an inverse technique. Geophys. Res. Lett. 2005, 32, L05608. [CrossRef]

23. Nakamura, H.; Ichikawa, H.; Nishina, A. Numerical study of the dynamics of the Ryukyu Current system. J. Geophys. Res. 2007, 112, C04016. [CrossRef]

24. Zhu, X.H.; Park, J.H.; Huang, D. Observation of baroclinic eddies southeast of Okinawa Island. Sci. China Ser. D 2008, 51, 1802-1812. [CrossRef]

25. Zhu, X.H.; Park, J.H.; Wimbush, M.; Yang, C.H. Comment on "Current system east of the Ryukyu Islands" by Nagano et al. J. Geophys. Res. 2008, 113, C03020. [CrossRef]

26. Whitehead, J.A.; Leetmaa, A.; Knox, R.A. Rotating hydraulics of strait and sill flows. Geophys. Fluid Dynam. 1974, 6, 101-125. [CrossRef]

27. Partt, L.J.; Lundberg, P.A. Hydraulic of rotating strait and sill flow, Annu Research. Fluid Mech. 1991, 23, 81-106. [CrossRef]

28. Qu, T.; Girton, J.B.; Whitehead, J.A. Deepwater overflow through Luzon Strait. J. Geophys. Res. 2006, 111, C01002. [CrossRef]

(C) 2020 by the authors. Licensee MDPI, Basel, Switzerland. This article is an open access article distributed under the terms and conditions of the Creative Commons Attribution (CC BY) license (http://creativecommons.org/licenses/by/4.0/). 